14 LOGOTHETIS, D. E., KURACHI, Y., GALPER, J., NEER, E. J. and CLAPHAM, D. E. (1987) Nature 325, 321-326

15 BIRNBAUMER, L. (1987) Trends Pharmacol. Sei. 8, 209-211

16 DIETZEL, C. and KURIAN, I. (1987) Cell 50, 1001-1010

17 WHITEWAY, M. et al. (1989) Cell 56, 467-477

18 LEBERER, E., DIGNARD, D., HOUGAN, L., THOMAS, D. Y. and WHITEWAY, M. (1992) EMBO/.11, 4805-4813

19 TANC, W-J. and GILMAN, A. G. (1991) Science 254,1500-1503

20 GAO, B. and GILMAN, A. G. (1991) Proc. Natl Acad. Sci. USA 88, 10178-10182

21 FEDERMAN, A. D., CONKLIN, B. R., SCHRADER, K. A., REED R. R. and BOURNE, H. R. (1992) Nature 356, 159-161

22 STERNWEIS, P. C. and SMRCKA, A. V. (1992) Trends Biochem. Sci. 17, 502-506

23 CAMPS, M., HOU, C. F., SIDIROPOULOS, D., STOCK, J. B., JAKOBS, K. H. and GIERSCHIK, P. (1992) Eur. J. Biochem. 206 $821-831$

24 SMRCKA, A. V. and STERNWEIS, P. C. J. Biol. Chem. (in press)

25 BLANK, J. L., BRATTAIN, K. A. and EXTON, I. H. (1992) J. Biol. Chem. 267, 23069-23075

26 HAGA, K. and HAGA, T. (1992) I. Biol. Chem. 267, 2222-2227

27 PITCHER, J. A. et al, (1992) Science 257, 1264-1267

28 LEE, R. H., TING, T. D., LIEBERMAN, B. S., TOBIAS, D. E.,
LOLLEY, R. N. and HO, Y. K. (1992) ). Biol. Chem. 267, 25104-25112

29 BAUER, P. H. et al. (1992) Nature 358, 73-76

30 LEE, R. H., LIEBERMAN, B. S., YAMANE, H. K., BOK, D. and FUNG, B. K-K. (1992) /. Biol. Chem. 267, 24776-2478

31 SCHMIDT, C. I., THOMAS, T. C., LEVINE, M. A. and NEER, E. J. (1992) /. Biol. Chem. 267, 13807-13810

32 FAWZI, A. B., FAY, D. S., MURPHY, E. A., TAMIR, H., ERDOS, J. J. and NORTHUP, J. K. (1991) ). Biol. Chem. 266, 12194-12200

33 LAW, S. F., MANNING, D. and REISINE, T. (1991) J. Biol. Chem. 266, 17885-17897

34 KLEUSS, C., HESCHELER, I., EWEL, C., ROSENTHAL, W., SCHULTZ, G. and WITTIG, B. (1991) Nature 353, 43-48

35 KLEUSS, C., SCHERUBL, H., HESCHELER, J., SCHULTZ, G. and WITTIC, B. (1992) Nature 358, 424-426

36 KLEUSS, C., SCHERUBL, H., HESCHELER, I., SCHULTZ, G. and WITTIG, B. (1993) Science 259, 832-834

37 BERSTEIN, G., BLANK, J. L., JHON, D. Y., EXTON, I. H., RHEE S. G. and ROSS, E. M. (1992) Cell 70, 411-418

38 DETERRE, P. and PFISTER, C. (1992) /. Biol. Chem. 267, 22018-22021

39 BRETTWIESER, G. E. and SZABO, C. (1988) J. Gen. Physiol. 91, $469-493$

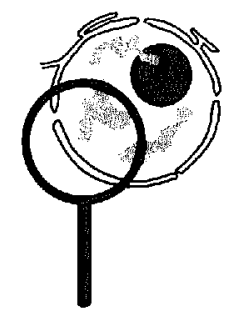

\section{Structure, function} and assembly of the nucleolus

\section{Urich Scheer, Mare Thiry and}

Gily coessems

Most events of ribosome biogenesis - such as transcription of the ribosomal RNA ( $r$ RNA) genes, processing of their primary transcripts into mature rRNAs and assembly with ribosomal and nonribosomal proteins to form the preribosomes - are confined to a special nuclear compartment, the nucleolus. Immunogold labelling and in situ hybridization at the ultrastructural level are providing novel insights into structure-function relationships of the nucleolus, and in vitro systems are beginning to shed light on the molecular mechanisms involved in the reforming of nucleoli

after mitosis.

Nucleoli, the sites of ribosome biogenesis, provide the most compelling evidence that there is order in the cell nucleus. The genes coding for ribosomal RNA (rRNA) and the transcription products of these genes are not randomly and diffusely distributed throughout the interphase nucleus, but instead are concentrated in a specific nuclear domain occupied by the nucleolus. Although extranucleolar genes and their RNA transcripts may also be localized to specific nuclear territories, nucleoli are a particularly good model for correlating molecular aspects of gene expression with nuclear structures.

A nucleolus is often regarded as a cluster of transcriptionally active rRNA genes surrounded by a cloud of densely packed transcription products in the form of preribosomal particles at various stages of their maturation pathway. According to this view, nucleolar structures are generated from rRNA. gene transcription units and locally accumulated products of transcription and ribosome assembly. However, this model ignores structural elements within nucleoli such as high-salt- and detergentresistant filaments that might be involved in the functional compartmentalization of the nucleolus (see Ref. 1 for a review). Furthermore, it is hardly compatible with the well-known fact that inhibition of transcription by drugs such as actinomycin $D$ does not lead to the disappearance of nucleoli. Under such conditions the nucleolar components lose most, if not all, resident pre-rRNAs and yet retain their characteristic ultrastructural features 2 . This observation underlines the importance of a structured framework as a primary determinant of nucleolar architecture and morphology. At first sight, the dynamic changes of the nucleolus accompanying mitosis, i.e. disassembly at prophase and reassembly at telophase, seem to argue against the presence of nucleolar structural elements. However, the fate of the nuclear lamina during mitosis clearly illustrates the cell's ability to induce extensive and rapid structural changes of karyoskeletal elements, probably by protein phosphorylation. 
Various aspects of rRNA gene transcription, processing of the primary transcripts into the mature rRNAs, and assembly of preribosomes have been reviewed recently ${ }^{3-5}$. Both pre-mRNA processing events and pre-rRNA maturation appear to be directed by small nuclear ribonucleoproteins (snRNPs), in all the species investigated from yeast to mammals ${ }^{6-8}$. The most abundant nucleolar snRNP contains U3 RNA and several proteins, including the evolutionarily highly conserved protein fibrillarin. How the processes of ribosome biogenesis may be linked to nucleolar structures has been examined in a number of recent articles ${ }^{9-14}$. At present, there is considerable controversy over the location of the rRNA genes within the nucleolar body (see below). In addition to ribosomal proteins, nucleoli contain a large number of nonribosomal proteins involved in various aspects of ribosome biogenesis and maintenance of nucleolar structure. Some of them have been characterlzed in detail and their biochemical properties and potential functions summarized 15 . The purpose of this review is to provide, against this background, a current view of the functional significance of the various nucleolar components during interphase, and their interactions during postmitotic formation of nucleoli, a process called nucleologenesis.

\section{Architecture of the interphase nucleolus}

When observed with the electron microscope (EM), nucleoli exhibit (with some exceptions) a strikingly similar organization from protists to humans. Generally, three morphologically distinct nucleolar components are recognized (Fig. 1a) ${ }^{9,16}$. The bulk of the nucleolus in metabolically active cells is made of particles resembling ribosomes, and is hence termed the granular component (GC). Within the granular mass are one or several rounded regions of low electron density, the fibrillar centres (FC). They are surrounded by a compact layer of densely staining fibrous material, the dense fibrillar component (DFC), which is especially prominent in plant cells. Nucleoli are generally surrounded by a shell of condensed nucleolus-associated chromatin which, in certain places, penetrates deeply into the nucleolar body through nucleolar interstices and reaches the FCs. Although in sections these nucleolar invaginations often appear as separate islands of intranucleolar chromatin, or interstices coritaining some chromatin strands, together they establish a structural continuity between the perinucleolar chromatin and the FCs ${ }^{16}$. Chromatin-filled interstices are often in direct contact with the surface of FCs, where they interrupt the layer of the DFC (Fig. 1a). As discussed below, highly decondensed chromatin fibres extend from these interstices into the FCs, where they can be traced only by specific detection methods in the EM.

How are these nucleolar structures linked to transcription of the rRNA genes, processing of the primary transcripts into mature $28 \mathrm{~S}, 18 \mathrm{~S}$ and $5.8 \mathrm{~S}$ rRNAs, and assembly with ribosomal and nonribosomal proteins into preribosomal subunits? It is generally thought that ribosome biogenesis is a vectorial process, which may be envisaged as an assembly line, beginning in the fibrillar part and continuing into the surrounding granular portion of the nucleolus.

\section{Tracing the rRNA genes}

There is considerable disagreement over the exact intranucleolar location of the transcribing rRNA genes 17,18. Several experimental strategies have been developed to approach this issue, which is of
Ulrich Scheer is at the Department of Cell and Developmental Biology, Theodor. Boveri-Institute, University of Würzburg, Am Hubland, D.8700 Würzburg, Germany; and Marc Thiry and Guy Goessens are at the Laboratory of Cell and Tissue Biology, University of Liège, rue de Pitteurs 20, B-4020 Liège, Belgium. 
paramount importance for understanding nucleolar architecture. EM autoradiographic ${ }^{16}$, cytochemical ${ }^{19,20}$ and immunocytochemical studies $12,20-22$ have clearly established the presence of DNA in the FCs of both plant and animal nucleoli. An extremely useful method for detecting DNA in ultrathin sections of conventionally fixed material, which combines high sensitivity with optimal structural preservation, exploits the ability of terminal deoxynucleotidyl transferase to add nucleotides to the free ends of DNA that are generated at the surface of the sections (Fig. 1b) ${ }^{22}$. To identify the intranucleolar DNA, nonradioactive in situ hybridizations for the EM have been performed by several groups. Some autilors have concluded that the rRNA genes are located exclusively in the FCs and in some masses of intranucleolar condensed chromatin 2,23-25; others have located the majority of the rRNA genes in the surrounding DFC 14,26. As discussed elsewhere 18 , the latter view most likely stems from an erroneous identification of the chromatin-containing interstices at the periphery of the FCs as part of the DFC. In fact, those interstices in close contact with the surface of the FCs may contain nontranscribed spacer sequences separating the tandemly repeated rRNA genes 24 , or even longer stretches of transcriptionally silent rDNA. Their striking association with the periphery of the FCs suggests that the transition from compacted and hence transcriptionally inactive chromatin into the extended chromatin of the FCs takes place here ${ }^{12,16}$.
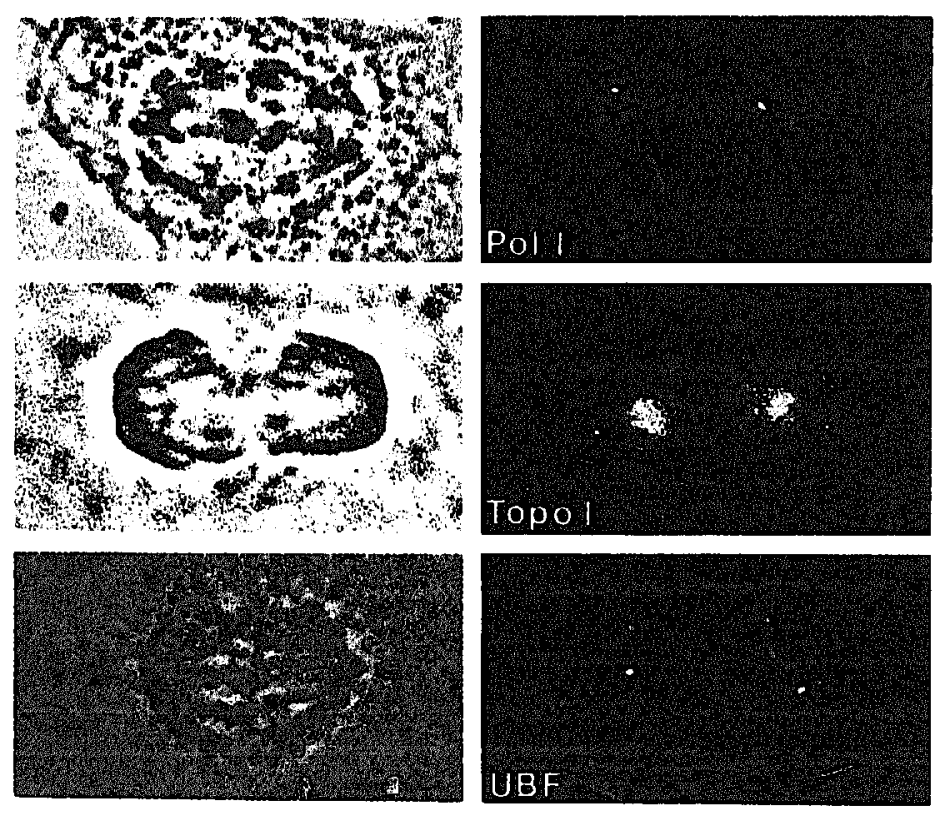

FIGURE 2

The chromosomal nucleolus-organizing regions (NORs) contain pol I, topo I and the transcription factor UBF, as shown by immunofluorescence microscopy of mitotic PtK2 cells (these cells, derived from a male kangaroo rat, have only one NOR located on the $X$ chromosome). Corresponding phase-contrast images are shown in the left panel. Bar, $10 \mu \mathrm{m}$.
FCs contain not only rDNA but also enzymes essential for transcription of the rRNA genes, notably RNA polymerase 1 (pol 1$)^{12,21,27}$ and DNA topoisomerase I (topo I) ${ }^{12,21}$. It has been proposed that the FCs merely store these enzymes, and that transcription actually takes place in the surrounding $D^{14}{ }^{14}, 17$. However, the reported absence of a nuclear pool of free pol I molecules ${ }^{28}$ clearly contradicts this view. Furthermore, the mouse nucleolar upstream binding factor (mUBF), a transcription factor required for the formation of stable initiation complexes by pol I (Ref. 29), is also enriched in the FC and absent in significant amounts from other regions of the nucleolus (Fig. 1c).

Earlier EM autoradiographic studies of cells pulse-labelled with ${ }^{3} \mathrm{H}$-labelled uridine revealed preferential incorporation of ${ }^{3} \mathrm{H}$ into the DFC. This result is usually taken as evidence for the origin of nascent rRNA in this nucleolar component ${ }^{9,14,17}$. However, after prolonged exposure of autoradiographs the FCs also appear labelled ${ }^{30}$. Hence the autoradiographic data are fully compatible with the view that pre-RNAs are synthesized in the FCs and accumulate transiently in the surrounding DFC. Further support for this notion comes from the demonstration of RNA and, more specifically, rRNA in the FCs by the polyadenylate transferase immunogold technique (Fig. 1d), immunolabelling with anti-RNA antibodies, and in situ hybridization ${ }^{31}$.

Taken together, all the available evidence points to the nucleolar FCs as the exclusive sites of the transcriptionally active rRNA genes. They must be extremely densely packed since a single rDNA transcription unit, as seen in Miller-type spread preparations, is as long as the entire nucleolus 12 . This hlgh packing density may provide a mechanism for bringing termination and initiation sites of the rRNA genes close together, thus maximizing transcriptional activity ${ }^{32}$.

It is tempting to speculate that a major function of the DFC is to establish a boundary around the FC that keeps the active rRNA genes together with the factors necessary for their transcription in this compartment. The DFC is not simply generated by the aggregation of transcription products but rather represents a distinct structure. Thus, when rRNA gene transcription is selectively inhibited by microinjection of antibodies to pol $I$, the DFC abandons the nucleolus and emerges in the nucleoplasm in the form of numerous dense fibrillar bodies $^{33}$. This behaviour illustrates that ongoing transcription of the rRNA genes is required to maintain the association of the DFC with the surface of the FCs.

\section{Relating ribosome production to nucleolar structures}

In situ hybridization studies in the EM, using appropriate hybridization probes, have made it possible to link each step of the pre-rRNA maturation pathway with nucleolar structures. However, results obtained with probes directed against transcribed spacer sequences should be interpreted 
with some reservation since it is difficult to assess whether the observed labelling reflects the distribution of pre-rRNAs or the excised fragments that might accumulate to some extent before being degraded. After their release from the template, the pre-rRNA transcripts transiently accumulate in the DFC, where primary processing events are thought to occur, before they pass into the surrounding $\mathrm{GC}^{2,13}$. The location of U3 snRNA in the DFC as well as the $\mathrm{GC}^{13,34}$ is consistent with its proposed role in early and late processing steps 6,7 . Although major proteins of the DFC such as nucleolin, fibrillarin and a phosphoprotein of $140 \mathrm{kDa}$ (nopp140) have been sequenced ${ }^{35}-40$, their precise functions remain to be explored. Nucleolin is associated (at least partly) with preribosomes 15 ; fibrillarin may play a role in pre-rRNA processing and the structural organization of the nucleolus 38 . A protein of $180 \mathrm{kDa}$ is thought to contribute to the general structure of the DFC ${ }^{41}$.

The GC contains preribosomal particles in later stages of the maturation pathway ${ }^{9}$. Although it is generally believed that the granular appearance of this nucleolar component reflects the presence of preribosomal particles, recent results ${ }^{2}$ raise some doubts about this correlation. When transcription is blocked by actinomycin $\mathrm{D}$, most of the pre-rRNA molecules leave the nucleolus but neither the granular component nor the DFC is lost. Hence it is conceivable that the granules form part of a structural framework of the nucleolus, providing support to preribosomes. Most of the ribosomal proteins are associated with maturing preribosomal subunits as well as some nonribosomal proteins, notably B23/NO38, whose primary structure has been determined $15,42,43$. It is striking that not only B23/NO38 but also nucleolin and nopp140 shuttle between the nucleus and cytoplasm, and hence may play a role in nucleocytoplasmic transport processes 40,43 . Now that antibodies against other ribosomal and nonribosomal proteins are available, a clearer picture of the order of protein addition during ribosome assembly should emerge in the near future.

\section{The chromosomal nucleolus organizer}

When cells of higher eukaryotes enter mitosis, the nucleoli disintegrate in various stages. The first component to disappear is the DFC, and this is followed by disappearance of the GC. Throughout mitosis the chromosomal nucleolus-organizing region (NOR), which harbours the tandemly repeated rRNA genes and reveals a striking morphological similarity to the FCs, persists ${ }^{16}$. The reformation of nucleoli at telophase follows the reverse order, i.e. the DFC forms around the NORs before the appearance of the $\mathrm{GC}^{16}$. The persistent association of pol I, topo I and the transcription factor UBF with the chromosomal NORs during mitosis (Fig. 2) indicates that NORs and nucleolar FCs are equivalent structures, thus confirming earlier conclusions based on morphological similarities and the presence of silver-binding proteins 16 . There have been reports that the DFC proteins nucleolin,
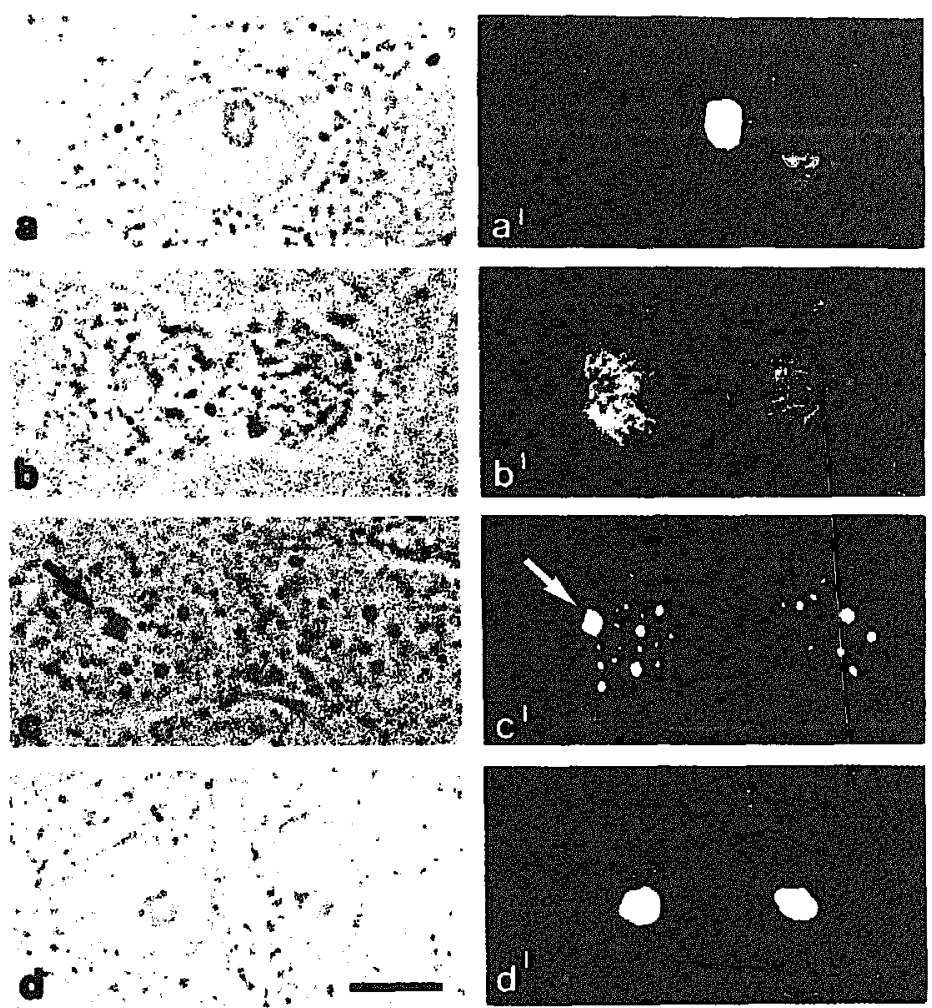

FICURE 3

Distribution of fibrillarin during mitosis of cultured PtK2 cells as revealed by immunofluorescence microscopy $\left(a^{\prime}-d^{\prime}\right)$. Corresponding phase-contrast images are also shown (a-d). In interphase cells $(a, d)$, fibrillarin is localized to the nucleoli. In metaphase and anaphase (b), fibrillarin uniformly coats the chromosome surfaces. in late telophase (c), the reforming nucleoli are stained (arrows) as well as numerous prenucleolar bodies. Bar, $10 \mu \mathrm{m}$.

fibrillarin and nopp140 are present in chromosomal NORs 15,44 . However, recent studies have falled to reproduce these observations ( $P$. Bell and U. Scheer, unpublished).

The absence of rRNA synthesis during mitosis, despite the continued presence of the transcriptional machinery, represents an extremely interesting case of gene regulation. Since the NOR-bound pol I can be reactivated by heparin, the enzyme apparently exists as an initiated complex with rDNA during mitosis 45 . At present the mechanisms that suppress or retard transcription of the rRNA genes during the mitotic block, and whether the nascent transcripts are actually ched from the template, are not known. The mitotic inhibition of IRNA synthesis may involve the recently identified pol I inhibitory activity in growth-arrested mouse cells; this factor does not affect the preinitiation complex, but inhibits later stages of rDNA transcription ${ }^{46}$.

\section{Postmitotic nucleolar assembly}

Nucleolar reformation begins at telophase with the formation of numerous prenucleolar bodies (PNBs) that contain several proteins characteristic of the DFC in functional nucleoli (see Ref. 47 for a 


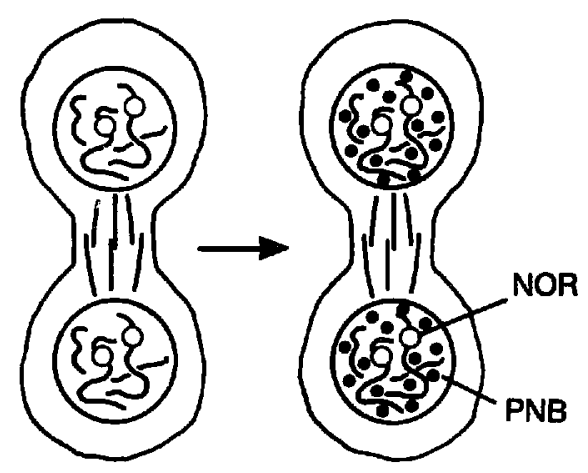

Formation of PNBs

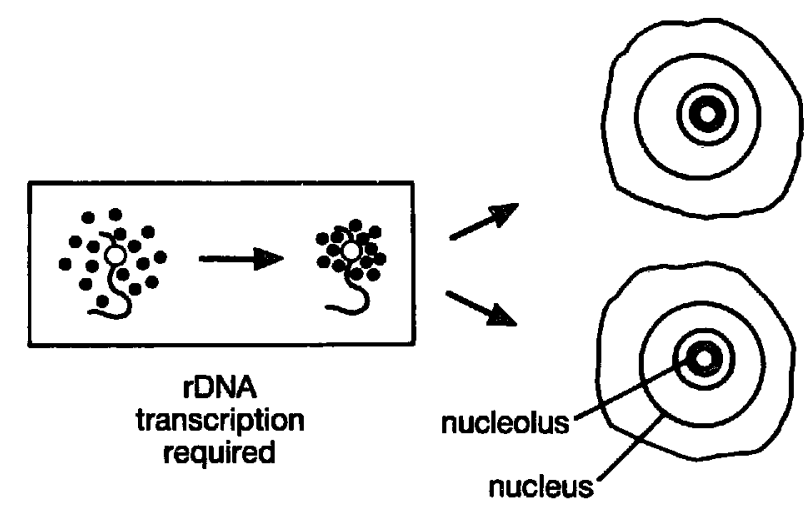

Interphase

Telophase

FIGURE 4

Schematic view of postmitotic nucleologenesis. Nucleolar reformation begins at telophase with the aggregation of nucleolar material, derived from the mother cell, into numerous prenucleolar bodies (PNBs). Subsequently the PNBs migrate towards the nucleolus-organizing region (NOR) where they eventually fuse to become the dense fibrillar component of the developing nucleolus. The site-specific fusion of the preformed nucleolar entities around the NOR requires transcriptional activity of the rRNA genes (boxed).

compilation of data). Figure 3 illustrates the distribution of one of these proteins, fibrillarin, during mitosis as seen by immunofluorescence microscopy. At metaphase and anaphase fibrillarin is uniformly associated with the surface of all chromosomes. At telophase, however, it appears in numerous PNBs. In a subsequent step these PNBs then coalesce around the chromosomal NOR(s) into the developing nucleolar body as illustrated schematically in Fig. 4. This site-specific fusion of the PNBs requires transcriptional activity of the rRNA genes. Exposure of cells to actinomycin $D^{48}$ or the topo-I-specific inhibitor campthotecin ${ }^{49}$, or microinjection of antibodies to pol I into mitotic cells $^{50}$, prevents the fusion of PNBs, which then remain dispersed throughout the nucleus (for similar results with plant cells see Ref. 51).

How are PNBs targeted to the NOR and induced to fuse and to become the DFC? Is the ability of the NOR to serve as a nucleation site in this as-
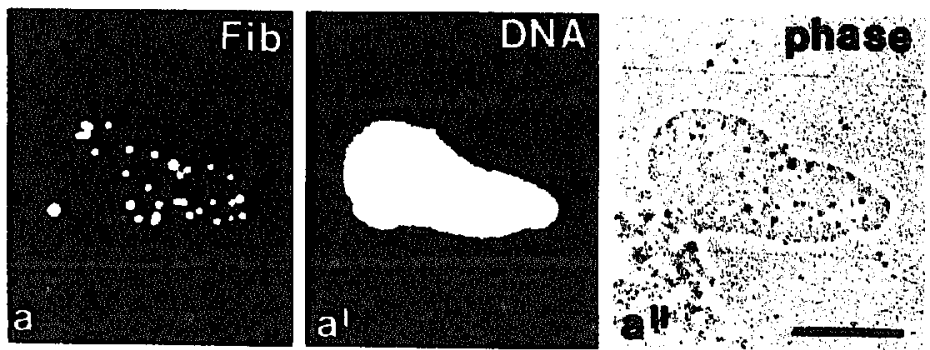

FIGURE 5

Nuclei reconstituted from lambda DNA in a Xenopus egg extract contain PNB-like bodies as revealed by immunofluorescence using antibodies against fibrillarin (a) and by phase-contrast microscopy (a"). The corresponding DNA-specific Hoechst fluorescence is also shown (a'). For details see Ref. 47.

Bar, $20 \mu \mathrm{m}$. sembly process an intrinsic property of the rDNAcontaining chromatin or a property of the nascent transcripts? In a revealing experiment Karpen et al.52 demonstrated that a single rRNA gene inserted randomly into the genome of Drosophila is sufficient to organize a functional nucleolus. Based on the association of fibrillarin with the free 5'-ends of nascent transcripts of the rRNA genes it was proposed that they may directly interact with the PNBs during nucleologenesis 12 . However, a truncated rRNA gene consisting of the promotor region, the 5 -external transcribed spacer and the adjacent $18 \mathrm{~S}$ sequences failet to organize a nucleolus 53 , indicating that nucleolar formation also requires the $28 \mathrm{~S}$ sequences.

\section{Early steps of nucleolar assembly in vitro}

Elucidation of the molecular mechanisms involved in nucleologenesis would be greatly facilitated by the availability of a cell-free system capable of reproducing this process. A first step in this direction was taken recently with the observation that nuclei assembled in Xenopus egg extract from purified DNA contain numerous distinct aggregates that are Indistinguishable from authentic PNBs by ultrastructural and compositional criteria 47 (an example is shown in Fig. 5). Removal of specific nucleolar proteins from the egg extract by immunodepletion showed that assembly of the PNB-like structures requires nucleolin and the $180 \mathrm{kDa}$ protein ${ }^{41}$ present in the DFC of Xenopus nucleoli, but is independent of fibrillarin (P. Bell, 1993, PhD thesis, University of Würzburg). So far, this experimental system allows the reproduction of the early steps of nucleologenesis up to the PNB stage. By reconstitution of nuclei around rDNA it should be feasible to establish conditions promoting the fusion of the pre-assembled PNBs into a coherent structure and to decipher the molecular inter- 
actions that take place between PNBs and transcribing rRNA genes during postmitotic nucleolar reformation.

\section{References}

1 BENAVENTE, R., KROHNE, C., SCHMIDT-ZACHMANN, M., HÜGLE, B. and FRANKE, W. W. (1984) I. Cell Sci. Suppl. 1, 161-186

2 PUVION-DUTilleUL, F., MAZAN, S., NICOLOSO, M., PICHARD, E., BACHELLERIE, J-P. and PICHARD, E. (1992) Eur. I. Cell Biol. 58, 149-162

3 GERBI, S., SAVINO, R., STEBBINS-BOAZ, B., JEPPESEN, C. and RIVERA-LEO N, R. (1990) in The Ribosome - Structure, Function and Evalution (Hill, W. E. et al., eds), pp. 452-469, American Society for Microbiology

4 REEDER, R. H. (1990) Irends Genet. 6, 390-395

5 SOLLNER-WEBB, B. and MOUCEY, E. B. (1991) Trends Biachem. Sci. 16, 58-62

6 KASS, S., KAZIMIERZ, T., STEITZ, J. A. and SOLLNER-WEBB, B. (1990) Cell 60, 897-908

7 SAVINO, R. and GERBI, S. A. (1990) EMBO /. 9, 2299-2308

8 FOURNIER, M. J. and MAXWELL, E. S. (1993) Trends Biochem. Sci. 18, 131-135

9 HADJIOLOV, A. A. (1985) The Nucleolus and Ribosome Biogenesis, Springer Verlag

10 SOMMERVILLE, J. (1986) Trends Biochem. Sci. 11, 438-442

11 WARNER, J. R. (1990) Curr. Opin. Cell Biol. 2, 521-527

12 SCHEER, U. and BENAVENTE, R. (1990) BioEssays 12, 14-21

13 FISCHER, D., WEISENBERCER, D. and SCHEER, U. (1991) Chromosomo 101, 133-140

14 SCHWARZACHER, H. G. and WACHTLER, F. (1991) Ann. Génét. $34,151-160$

15 OLSON, M. O. I. (1990) in The Eukaryotic Nucleus, Val. 2 (Strauss, P. R. and Wilson, S. H., eds), pp. 519-559, The Telford Press

16 GOESSENS, G. (1984) Int. Rev, Cytol. 87, 107-158

17 JORDAN, E. G. (1991) I. Cell Sci. 98, 437-442

18 THIRY, M. and COESSENS, M. (1992) Exp. Cell Res. 200, 1 -4

19 DERENZINI, M., THIRY, M. and COESSENS, M. (1990) 1. Histochem. Cytochem. 38, 1237-1256

20 MOTTE, P. M., LOPPES, R., MENAGER, M. and DELTOUR, R. (1991) 1. Histochem. Cytochem, 39, 1495-1506

21 THIRY, M., SCHEER, U. and GOESSENS, G. (1991) Electron Microsc. Rev. 4, 85-110

22 THIRY, M., PLOTON, D., MENAGER, M. and GOESSENS, G. (1993) Cell Tissue Res. 271, 33-45

23 THIRY, M. and THIRY-BLAISE, L. (1989) Eur. J. Cell Biol. 50 , 235-243

24 THIRY, M. and THIRY-BLAISE, L. (1991) Nucleic Acids Res. 19, $11-15$

25 PUVION-DUTILLEUL, F., BACHELLERIE, J-P. and PUVION, E. (1991) Chromosomo 100, 395-409

26 WACHTLER, F. et al. (1992) Exp. Cell Res. 198, 135-143

27 SCHEER, U. and ROSE, K. M. (1984) Proc. Natl Acad. Sci. USA 81, 1431-1435

28 HALLECK, M. S., SCHLEGEL, R. A. and ROSE, K. M. (1989) J. Cell Sci. 92, 101-109

29 VOIT, R. et al. (1992) EMBOJ. 11, 2211-2218

30 THIRY, M. and GOESSENS, G. (1991) /. Cell Sci. 99, 759-767

31 THIRY, M. (1992) Nucleic Acids Res. 20, 6195-6200

32 JOHNSON, S. P. and WARNER, J. R. (1989) Mol. Cell. Biol. 9, 4986-4993

33 BENAVENTE, R., REIMER, G., ROSE, K. M., HÜGLE-DÖRR, B. and SCHEER, U. (1988) Chromosoma 97, 115-123
34 PUVION-DUTILLEUL, F., MAZAN, S., NICOLOSO, M., CHRISTENSEN, M. E. and BACHELLERIE, J-P. (1991) Eur. I. Cell Biol. 56, 178-186

35 LAPEYRE, B., BOURBON, H. and AMALRIC, F. (1987) Proc, Natl Acad. Sci. USA 84, 1472-1476

36 LAPEYRE, B. et al. (1990) Mol. Cell. Biol. 10, 430-434

37 CAIZERCUES-FERRER, M. et al. (1989) Genes Dev. 3, 324-333

38 JANSEN, R. P. et al. (1991) /. Cell Biol. 113, 715-729

39 ARIS, I. P. and BLOBEL, G. (1991) Proc. Nat/ Acad. Sci. USA 88, 931-935

40 MEIER, U. T. and BLOBEL, G. (1992) Cell 70, 127-138

41 SCHIMIDT-ZACHMANN, M., HÜCLE, B., SCHEER, U. and FRANKE, W. W. (1984) Exp. Cell Res. 153, 327-346

42 SCHMIDT-ZACHMANN, M., HÜCLE-DÖRR, B., SCHEER, U. and FRANKE, W. W. (1987) EMBO I. 6, 1881-1890

43 BORER, R. A., LEHNER, C. F., EPPENBERGER, H. M. and NICG, E. A. (1989) Cell 56, 379-390

44 MEIER, U. T. and BLOBEL, C. (1990) I. Cell Biol. 111, 2235-2245

45 MATSUI, S. and SANDBERG, A. A. (1985) Chromosoma 92, 1-6

46 KERMEKCHIEV, M. and MURAMATSU, M. (1993) Nucleic Acids Res. 21, 447-453

47 BELL, P., DABAUVALLE, M-C. and SCHEER, U. (1992) /. Cell Biol. $118,1297-1304$

48 OCHS, R. L., LISCHWE, M. A., SHEN, E., CARROLL, R. E. and BUSCH, H. (1985) Chromosoma 92, 330-336

49 WEISENBERCER, D., SCHEER, U. and BENAVENTE, R. EUr. I. Cell Biol, (in press)

50 BENAVENTE, R., ROSE, K. M., REIMER, H., HÜGLE-DÖRR, B. and SCHEER, U. (1987) I. Cell Biol. 105, 1483-1491

51 DE LA TORRE, C. and GIMENEZ-MARTIN, G. (1982) in The Nucleolus (Jordan, E. G. and Cullis, C. A., eds), pp. 153-177, Cambridge University Press

52 KARPEN, G. H., SCHAEFER, I. E. and LAIRD, C. D. (1988) Genes Dev. 2, 1745-1763

53 MCKEE, B. D., HABERA, L. and VRANA, J. A. (1992) Genetics $132,529-544$

Acknowledgements

We thank

I. Grummt,

U. T. Meyer and

G. Reimer for anti-

bodies; H. Merkert and F. Skivée for

skilful technical assistance; and

R. Benavente and

P. Bell for helpful

discussions. Work

in the authors'

laboratories was

supported by grants from the

Deutsche

Forschungs-

gemeinschaft

(Sche 157/8-1)

the Fonds de la

Recherche

Scientifique

Médicale

(3.4512.90) and

the Actions de

Recherche

Concertées

(91/95-152).
The next article in the series on nuclear structures involved in RNA biogenesis is scheduled to appear in the September issue of TCB.

\section{REVIEWS}

Reviews in Trends in Cell Biology aim to provide objective, authoritative and concise overviews of recent progress in a research area of broad interest. Review articles are usually commissioned by the Editor. The submission of completed reviews without prior consultation is discouraged. All reviews are sent to recognized specialists for refereeing and are subject to stringent editing before being accepted for publication: commissioning does not guarantee publication. 